\title{
Parenting style in childhood and mortality risk at older ages: a longitudinal cohort study
}

Panayotes Demakakos, Demetris Pillas, Michael Marmot and Andrew Steptoe

\section{Background}

Parenting style is associated with offspring health, but whether it is associated with offspring mortality at older ages remains unknown.

\section{Aims}

We examined whether childhood experiences of suboptimal parenting style are associated with increased risk of death at older ages.

\section{Method}

Longitudinal cohort study of 1964 community-dwelling adults aged 65-79 years.

\section{Results}

The association between parenting style and mortality was inverse and graded. Participants in the poorest parenting style score quartile had increased risk of death (hazard ratio $(\mathrm{HR})=1.72,95 \% \mathrm{Cl} 1.20-2.48)$ compared with those in the optimal parenting style score quartile after adjustment for age and gender. Full adjustment for covariates partially explained this association $(H R=1.49,95 \% \mathrm{Cl} 1.02-2.18)$. Parenting style was inversely associated with cancer and other mortality, but not cardiovascular mortality. Maternal and paternal parenting styles were individually associated with mortality.

\section{Conclusions}

Experiences of suboptimal parenting in childhood are associated with increased risk of death at older ages.

\section{Declaration of interest}

None.

\section{Copyright and usage}

(c) The Royal College of Psychiatrists 2016.
A strong theoretical and empirical basis supports the adoption of a life-course framework to explain health and disease in later life. ${ }^{1}$ Evidence implicates early life and childhood exposures in metabolic disorders, cardiovascular disease, psychopathology and premature death in adulthood. ${ }^{2-7}$ The long-term effects of early life exposures, such as poor diet during gestation, on later life cardiovascular and metabolic outcomes are well established. ${ }^{2}$ Disease susceptibility that stems from experiences of abuse, neglect and material deprivation during childhood and consequent mortality have also been studied. ${ }^{4-9}$ Further, poor parenting has been associated with adverse outcomes in childhood and adolescence including dysregulation of the hypothalamic-pituitary-adrenal (HPA) axis, ${ }^{10-12}$ obesity, ${ }^{13}$ poor academic achievement, maladaptation, problem behaviour and aggression ${ }^{14,15}$ as well as adult psychopathology. ${ }^{16}$ Despite the potential importance of parenting as a life-course determinant of health and disease, the link between experiences of parenting in childhood and survival in later life, where most of deaths occur, has yet to be investigated. We studied whether experiences of parenting style in childhood are associated with survival in a national sample of older people. Since parenting style influences the entire period from birth to adolescence, which spans the most sensitive periods of cognitive, behavioural and socioemotional development, we hypothesised that poor parenting style characterised by lack of affection and care and overprotection and lack of autonomy ${ }^{17}$ would be associated with increased risk of all-cause and cause-specific mortality.

\section{Method}

\section{Study population}

The English Longitudinal Study of Ageing is a prospective observational study of community-dwelling people aged 50 years and over in England. At baseline, in 2002-2003, the sample comprised 11391 core members and was nationally representative. Follow-up interviews took place biennially after the baseline.
A one-off life-history survey that gathered retrospective information about the experiences and life circumstances of the participants, from birth to age 50 years, took place in 2007 as an add-on to the second follow-up interview. The English Longitudinal Study of Ageing is approved by the National Research Ethics Service (MREC/01/2/91) and all participants have provided informed consent. A detailed description of the study can be found at: http://www.elsa-project.ac.uk/.

For the needs of our study, we used data from both the main study and the life-history survey. Because of the potential importance of generational differences in experiences of parenting style and the inability to distinguish between age and cohort effects in our data, we confined our analysis to participants aged 65 to 79 years in 2007. To eliminate the possibility of experiences of individuals who were reared by a single parent or non-natural parents confounding our results, we excluded participants who did not report on the parenting style of both natural parents. Of the 7535 core members who had participated in the second follow-up interview, 6199 participated in the life-history survey of which 2744 were aged 65 to 79 years. The analytic sample comprised 1964 participants, after the exclusion of those who did not complete the childhood experiences questionnaire $(n=312)$; were not reared by both natural parents or did not report on the parenting style of both natural parents $(n=253)$; or had missing values in any of the variables used in the analysis $(n=215)$. Non-response to the life-history survey was associated with lower socioeconomic position, poorer health, not living alone and non-White ethnicity.

\section{Assessment of perceived parenting style}

Parenting style was measured using the seven-item Parental Bonding Instrument (PBI) during the life-history survey in 2007. ${ }^{17,18}$ The PBI is one of the most widely used measures of parenting style. Conceptually, it draws on the works of Bowlby 
and Rutter on the importance of mothering and the bond between a parent and a child and was created to measure the parental contribution to a parent-child bond. ${ }^{17}$ The PBI is designed to retrospectively assess adults' perceptions of their parents' parenting style and examine two fundamental dimensions of parenting, care and overprotection. ${ }^{17}$ In our study, the PBI referred to the period when the participants were aged 15 years or younger. The seven-item PBI includes three care items (i.e. understood my problems and worries, emotionally cold mother/ father, and made me feel not wanted) and four overprotection items (i.e. let me do things I liked, liked me to make decisions, made me feel dependent on them and were overprotective). The four-point response scale ranges from 'strongly agree' to 'strongly disagree'. According to the PBI scoring system, optimal parenting is characterised by high care and low overprotection scores. The full 25-item PBI has good psychometric properties ${ }^{19}$ and demonstrates good stability over extended time periods in non-clinical samples. ${ }^{20}$ The psychometric properties of the seven-item PBI are comparable with those of the full 25 -item PBI. ${ }^{18}$ The PBI has been used to predict psychopathology; parental coldness and low levels of parental care have been shown to be consistently associated with depression and other mental health conditions in a non-specific manner. $^{21-23}$ Parental overprotection is also associated with mental health problems, ${ }^{21,23}$ but evidence on this association is less consistent. ${ }^{22}$

Parenting style scores were separately derived for the mother and father. They ranged from 0 (poorest parenting style: lowest levels of care and highest levels of overprotection) to 21 (optimal parenting style: highest levels of care and lowest levels of overprotection). The overall parenting style score, which was derived by aggregating the maternal and paternal parenting style scores, ranged from 0 (poorest parenting style) to 42 (optimal parenting style). Data on the distributions of the overall parenting style score and subscale scores are presented in online Table DS1. To avoid unnecessarily excluding individuals with few missing values, we substitute up to one missing value per subscale per parent with the respective mean score. Thus, the maternal and paternal parenting style scores included participants with up to two imputed values and the overall parenting style score included participants with up to four imputed values. Because the imputed and observed parenting style data produced directly comparable results, we used the former in the main analysis and present the analysis that is based on the latter in online Table DS2). To explore whether the association between parenting style and mortality was dose-response we categorised the scores into quartiles.

\section{Mortality}

Mortality data were obtained from the Office for National Statistics central registry for all consenting participants (approximately 95.5\% of the sample, http://www.ons.gov.uk/). Information on causes of death was available up to February 2013. The ICD-10 was used to classify deaths. ${ }^{24}$ Deaths with ICD-10 codes from C00 to C97 were classified as cancer deaths and deaths with ICD-10 codes from I00 to 199 as cardiovascular deaths. All remaining deaths were classified as 'other'.

\section{Covariates}

Age, gender and measures of self-reported childhood socioeconomic position were used as confounders. Marital status, parenthood status, measures of adult socioeconomic position, and negative (i.e. elevated depressive symptoms that were defined as $\geqslant 4$ symptoms on the eight-item Center for Epidemiological Studies-Depression scale ${ }^{25}$ ) and positive affect (i.e. tertiles of the five-item pleasure subscale score of the 19-item CASP (control, autonomy, self-realisation, pleasure) scale,${ }^{26}$ which included items like 'On balance, I look back on my life with a sense of happiness' and 'I enjoy the things that I do') were also used as confounders. Categories of body mass index (BMI, weight $(\mathrm{kg}) / \mathrm{height}^{2}\left(\mathrm{~m}^{2}\right)$ ) and waist circumference $(\mathrm{cm})$, smoking (never a smoker, ex-smoker, current smoker), physical activity on a weekly basis (not at all, mild, moderate, vigorous), memory (tertiles of the summary score of immediate and delayed 10-word recall), social support (low $v$. high) from partner, children, relatives and friends, and number of problems with social relationships were used as potential mediators. All covariates were measured in 2006-2007, except for BMI and waist circumference, which were measured in 2004-2005.

\section{Statistical analysis}

We calculated mortality rates according to quartiles of parenting style scores. We estimated Cox proportional hazards regression models of the associations between quartiles of the parenting style score and all-cause and cause-specific mortality. Survival time (in months) was the time that elapsed from the date of life-history interview, in 2007, to the first of either the date of death or censoring i.e. February 2013. We used the pooled sample to estimate the models as there was no significant interaction by gender. The models were initially adjusted for age and gender, then for childhood socioeconomic position, and then in addition for marital and parenthood statuses, adult socioeconomic position, positive and negative affect, obesity, unhealthy behaviours, cognitive function and social factors. We used the same methodology and sample to estimate models of the associations between maternal and paternal parenting style scores and all-cause mortality. In supplementary analyses (Table DS3), we also estimated models of the associations between parental care and overprotection scores and all-cause mortality. We ascertained that the proportionality assumption was met using survival plots and the Schoenfeld residuals test. To ascertain that our results are not driven by adverse childhood experiences and childhood health problems, in supplementary analyses, we additionally adjusted our models for self-reported adverse childhood experiences including parental mental health and addiction problems (Table DS4) and self-reported childhood health problems that are known to affect parenting (i.e. epilepsy, asthma, diabetes, hearing problems, limiting disability and emotional, nervous or psychiatric problems) (Table DS5). In additional supplementary analyses, we explored baseline self-reported comorbidities (i.e. heart disease, stroke, cancer, psychiatric problems and chronic lung disease) as potential confounders (Table DS6) and inflammatory markers (i.e. fibrinogen and high sensitivity C-reactive protein) that were measured in 2004-2005 as potential mediators (Table DS7). Further, to minimise the chances of reverse causality (i.e. proximity to the death influencing parenting style reports), we estimated models that excluded all deaths that occurred within the first 24 months after the baseline in 2007 (Table DS8).

\section{Results}

Participants who reported being raised with a poor parenting style (i.e. those who were in the poorest parenting style score quartile) were more likely to be female and slightly younger, to live in a household with fewer books at age 10 years, to be less happy and report more depressive symptoms and problems with social relationships and less social support compared with those who reported being raised with a good parenting style (i.e. those who were in the optimal parenting style score quartile) (Table 1). 
Table 1 Baseline characteristics according to parenting style score

\begin{tabular}{|c|c|c|c|c|c|}
\hline & \multicolumn{5}{|c|}{ Parenting style score quartiles ${ }^{a}$} \\
\hline & $\begin{array}{l}\text { Optimal } \\
(n=498)\end{array}$ & $\begin{array}{l}\text { Second optimal } \\
\qquad(n=449)\end{array}$ & $\begin{array}{l}\text { Second poorest } \\
\qquad(n=485)\end{array}$ & $\begin{array}{l}\text { Poorest } \\
(n=532)\end{array}$ & $P^{\mathrm{b}}$ \\
\hline Age, mean (s.d.) & $71.6(4.1)$ & $71.8(4.1)$ & $71.4(4.2)$ & $71.0(4.1)$ & 0.010 \\
\hline Male, $n$ (\%) & $246(49.4)$ & $205(45.7)$ & $247(50.9)$ & $219(41.2)$ & 0.009 \\
\hline Non-married, $n$ (\%) & $136(27.3)$ & $133(29.6)$ & $162(33.4)$ & $183(34.4)$ & 0.054 \\
\hline Childless (without any children), $n$ (\%) & $48(9.6)$ & $42(9.4)$ & $55(11.3)$ & $55(10.3)$ & 0.75 \\
\hline No educational qualifications, $n$ (\%) & $156(31.3)$ & $137(30.5)$ & $180(37.1)$ & $178(33.5)$ & 0.65 \\
\hline Lowest total net household wealth tertile $(<£ 143,000), n(\%)$ & $131(26.3)$ & $124(27.6)$ & $127(26.2)$ & $162(30.5)$ & 0.21 \\
\hline First ever residence was rented, ${ }^{\mathrm{C}} n(\%)$ & $362(74.0)$ & $297(70.1)$ & $351(74.4)$ & $365(71.0)$ & 0.36 \\
\hline$\leqslant 10$ books at the household at age 10 years, ${ }^{\mathrm{c}} n(\%)$ & $114(24.1)$ & $112(26.4)$ & $149(31.8)$ & $189(37.1)$ & $<0.001$ \\
\hline $\begin{array}{l}\text { Father/main carer in manual occupation or unemployed at age } \\
14 \text { years, } n(\%)\end{array}$ & \multicolumn{4}{|c|}{ Father/main carer in manual occupation or unemployed at age } & 0.42 \\
\hline Current smoker, $n(\%)$ & $57(11.5)$ & $46(10.2)$ & $43(8.9)$ & $60(11.3)$ & 0.21 \\
\hline Physically inactive, $n$ (\%) & $31(6.2)$ & $30(6.7)$ & $34(7.0)$ & $40(7.5)$ & 0.13 \\
\hline Body mass index $\geqslant 30 \mathrm{~kg} / \mathrm{m}^{2},{ }^{\mathrm{c}} n(\%)$ & $114(25.9)$ & $107(27.0)$ & $113(26.6)$ & $150(32.1)$ & 0.51 \\
\hline Waist circumference $\geqslant 102 \mathrm{~cm}$ (in men) $/ \geqslant 88 \mathrm{~cm}$ (in women), ${ }^{\mathrm{c}} n(\%)$ & $233(52.5)$ & $218(54.0)$ & $220(50.8)$ & $253(52.9)$ & 0.74 \\
\hline Lowest tertile of cognitive function ( $\leqslant 8$ recalled words) , $n$ (\%) & $153(30.7)$ & $143(31.9)$ & $150(30.9)$ & $166(31.2)$ & 0.67 \\
\hline Low social support, ${ }^{\mathrm{c}} n(\%)$ & $103(21.5)$ & $152(35.2)$ & $159(34.2)$ & $211(42.9)$ & $<0.001$ \\
\hline Problems with more than one type of social relationships, ${ }^{c} n(\%)$ & $30(6.3)$ & $46(10.7)$ & $48(10.4)$ & $98(20.0)$ & $<0.001$ \\
\hline Elevated depressive symptoms ( $\geqslant 4$ symptoms), $n(\%)$ & $39(7.8)$ & 49 (10.9) & $61(12.6)$ & $91(17.1)$ & $<0.001$ \\
\hline Lowest positive affect score tertile (positive affect score $\leqslant 12$ ) ${ }^{\mathrm{C}} n(\%)$ & $74(16.0)$ & $92(21.9)$ & $125(27.2)$ & $162(33.8)$ & $<0.001$ \\
\hline \multicolumn{6}{|c|}{$\begin{array}{l}\text { a. Parenting style score ranged from } 0 \text { (poorest style) to } 42 \text { (optimal style). Optimal quartile: score }>34 \text {; second optimal quartile: score from }>31 \text { to } \leqslant 34 \text {; second poorest quartile: } \\
\text { score from }>27 \text { to } \leqslant 31 \text {; and poorest quartile: score } \leqslant 27 \text {. } \\
\text { b. } P \text {-values are generated using chi-square, Kruskal-Wallis and analysis of variance tests for categorical, ordinal and continuous covariates, respectively. } \\
\text { c. The calculation of estimates and } P \text {-values was based only on participants with valid values and did not include the category of missing values. }\end{array}$} \\
\hline
\end{tabular}

A total of 243 deaths were observed over a mean follow-up of 5.4 years (median 5.7 years). In the unadjusted Cox model, people in the poorest parenting style score quartile had a $50 \%$ higher risk of death compared with those in the optimal parenting style score quartile (Table 2). Age exerted a negative confounding effect and adjustment for it increased the strength of the association. Adjustment for childhood socioeconomic position explained a part of the association. In the fully adjusted model, participants in the poorest parenting style score quartiles had a $49 \%$ higher risk of death compared with those in the optimal parenting style score quartile. The associations between parenting style and cancer and other mortality were also strong and significant (Table 2). Full adjustment for covariates explained the association between parenting style and cancer mortality, but not the association between parenting style and other mortality. Parenting style was not associated with cardiovascular mortality. Maternal and paternal parenting style scores were also inversely associated with all-cause mortality (Table 3 ). These associations were explained after adjustment for all covariates.

Supplementary analyses indicated that the associations between parenting style and all-cause and cause-specific mortality were not affected by additional adjustment for adverse childhood experiences, childhood health problems and baseline comorbidities, except for a modest effect of parental psychopathology on the association between parenting style and other mortality. They also indicated that fibrinogen, but not C-reactive protein, explained a small part of the association between parenting style and all-cause mortality. Sensitivity analyses that excluded deaths that occurred within the first 24 months after the baseline produced comparable but stronger results to those of the main analysis.

\section{Discussion}

In a national sample of people aged 65 to 79 years we found that experiences of parenting style in childhood were associated with all-cause mortality. This association was inverse and graded. People who reported being raised with a poor parenting style had increased risk of death compared with those who reported being raised with an optimal parenting style. The risk of death was also increased for people who reported being raised with an intermediate parenting style, which was not the poorest, but also fell short of being optimal. Parenting style was also inversely associated with increased risk of cancer and other mortality, but not cardiovascular mortality. Full adjustment for childhood and adult socioeconomic position, and adult demographic, psychosocial, cognitive and behavioural factors partially explained the association between parenting style and all-cause and other mortality and fully the association between parenting style and cancer mortality. Poor maternal and paternal parenting styles, low levels of parental care and high levels of parental overprotection were individually associated with increased risk of death. Notwithstanding any overlap, their effect on the risk of death in later life is likely to be additive as they all appeared to contribute to the association between parenting style and death.

\section{Findings from other studies}

To our knowledge, our study is the first to examine the association between parenting style and risk of death in a national sample of older people. Studies have examined parental abuse and neglect, but not parenting style, and mortality mostly in adults younger than 60 years. ${ }^{6,7,27,28}$ Most $^{7,27,28}$ but not all ${ }^{6}$ of these studies reported a positive association between adverse childhood experiences and the risk of death. This evidence largely concurs with our findings both in terms of direction of causality and magnitude of the associations. A study of a cohort of US male medical students has also generated findings that concur with ours; they found a significant inverse association between the quality of the father-son relationship and the risk of incident cancer. $^{29}$ 
Parenting style score quartiles ${ }^{b}$

\begin{tabular}{|c|c|c|c|c|}
\hline & \\
\hline & Optimal & Second optimal & Second poorest & Poorest \\
\hline \multicolumn{5}{|l|}{ All-cause mortality } \\
\hline Deaths, $n$ & 48 & 51 & 69 & 75 \\
\hline Deaths/1000 person-years (95\% Cl) & $17.7(13.3-23.4)$ & 20.9 (15.9-27.5) & $26.5(20.9-33.6)$ & $26.5(21.1-33.2)$ \\
\hline Model 1, HR (95\% Cl) & 1.00 (reference) & $1.18(0.80-1.75)$ & $1.50(1.04-2.17)$ & $1.50(1.05-2.16)$ \\
\hline Model 2, HR (95\% Cl) & 1.00 (reference) & $1.20(0.81-1.77)$ & $1.54(1.07-2.23)$ & $1.72(1.20-2.48)$ \\
\hline Model 3, HR (95\% Cl) & 1.00 (reference) & $1.13(0.76-1.68)$ & $1.45(1.00-2.10)$ & $1.59(1.10-2.30)$ \\
\hline Model 4, HR (95\% Cl) & 1.00 (reference) & $1.16(0.78-1.74)$ & $1.43(0.98-2.09)$ & $1.49(1.02-2.18)$ \\
\hline \multicolumn{5}{|l|}{ Cardiovascular mortality } \\
\hline Deaths, $n$ & 17 & 13 & 18 & 18 \\
\hline Deaths/1000 person-years (95\% Cl) & $6.3(3.9-10.1)$ & $5.3(3.1-9.2)$ & $6.9(4.4-11.0)$ & $6.4(4.0-10.1)$ \\
\hline Model 1, HR (95\% Cl) & 1.00 (reference) & $0.85(0.41-1.75)$ & $1.11(0.57-2.15)$ & $1.02(0.53-1.98)$ \\
\hline Model 2, HR (95\% Cl) & 1.00 (reference) & $0.85(0.41-1.74)$ & $1.16(0.60-2.25)$ & $1.21(0.62-2.36)$ \\
\hline Model 3, HR (95\% Cl) & 1.00 (reference) & $0.78(0.38-1.62)$ & $1.05(0.54-2.06)$ & $1.04(0.53-2.04)$ \\
\hline Model 4, HR $(95 \% \mathrm{Cl})$ & 1.00 (reference) & $0.82(0.38-1.75)$ & $1.16(0.58-2.33)$ & $1.03(0.51-2.10)$ \\
\hline \multicolumn{5}{|l|}{ Cancer mortality } \\
\hline Deaths, $n$ & 21 & 24 & 28 & 35 \\
\hline Deaths/1000 person-years (95\% Cl) & $7.7(5.0-11.9)$ & $9.8(6.6-14.7)$ & $10.8(7.4-15.6)$ & $12.4(8.9-17.2)$ \\
\hline Model 1, HR (95\% Cl) & 1.00 (reference) & $1.27(0.71-2.28)$ & $1.39(0.79-2.46)$ & $1.60(0.93-2.75)$ \\
\hline Model 2, HR (95\% Cl) & 1.00 (reference) & $1.29(0.72-2.32)$ & $1.41(0.81-2.49)$ & $1.77(1.03-3.05)$ \\
\hline Model 3, HR (95\% Cl) & 1.00 (reference) & $1.21(0.67-2.19)$ & $1.39(0.79-2.45)$ & $1.73(1.00-2.99)$ \\
\hline Model 4, HR $(95 \% \mathrm{Cl})$ & 1.00 (reference) & $1.15(0.64-2.10)$ & $1.25(0.70-2.22)$ & $1.47(0.84-2.59)$ \\
\hline \multicolumn{5}{|l|}{ Other mortality } \\
\hline Deaths, $n$ & 10 & 14 & 23 & 22 \\
\hline Deaths/1000 person-years (95\% Cl) & $3.7(2.0-6.8)$ & $5.7(3.4-9.7)$ & $8.8(5.9-13.3)$ & $7.8(5.1-11.8)$ \\
\hline Model 1, HR (95\% Cl) & 1.00 (reference) & $1.56(0.69-3.51)$ & $2.41(1.15-5.06)$ & $2.12(1.00-4.47)$ \\
\hline Model 2, HR (95\% Cl) & 1.00 (reference) & $1.59(0.70-3.54)$ & $2.47(1.19-5.23)$ & $2.48(1.17-5.25)$ \\
\hline Model 3, HR (95\% Cl) & 1.00 (reference) & $1.56(0.69-3.53)$ & $2.27(1.08-4.78)$ & $2.26(1.06-4.81)$ \\
\hline Model 4, HR (95\% Cl) & 1.00 (reference) & $1.69(0.73-3.94)$ & $2.36(1.08-5.18)$ & $2.46(1.10-5.45)$ \\
\hline \multicolumn{5}{|l|}{ Sample sizes } \\
\hline Participants, $n$ & 498 & 449 & 485 & 532 \\
\hline Person-years of follow-up & 2719 & 2443 & 2602 & 2838 \\
\hline \multicolumn{5}{|c|}{$\begin{array}{l}\text { a. Model 1: this is the unadjusted association; model 2: adjusted for age and gender; model } 3 \text { as model } 2 \text {, plus adjustment for childhood socioeconomic position (i.e. ownership of } \\
\text { the first-ever permanent residence, number of books in the household at age } 10 \text { years, and father's or main carer's occupational class at age } 14 \text { years); model } 4 \text { : as model } 3 \text {, plus } \\
\text { adjustment for adult socioeconomic position (i.e. education and total net household wealth), marital status, parenthood status, obesity (i.e. body mass index and waist circumference), } \\
\text { cognitive function, unhealthy behaviours (i.e. smoking and physical activity), social factors (i.e. social support and number of problems with social relationships), elevated depressive } \\
\text { symptoms and positive affect. } \\
\text { b. Parenting style score ranged from o (poorest style) to } 42 \text { (optimal style). Optimal quartile: score }>34 \text {; second optimal quartile: score from }>31 \text { to } \leqslant 34 \text {; second poorest quartile: } \\
\text { score from }>27 \text { to } \leqslant 31 \text {; and poorest quartile: score } \leqslant 27 \text {. }\end{array}$} \\
\hline
\end{tabular}

Table 3 All-cause mortality hazard ratios according to maternal and paternal parenting style scores ${ }^{a}$

Parenting style score quartiles ${ }^{\text {b }}$

\begin{tabular}{|c|c|c|c|c|}
\hline & \multicolumn{4}{|c|}{ Parenting style score quartiles ${ }^{\text {b }}$} \\
\hline & Optimal & Second optimal & Second poorest & Poorest \\
\hline \multicolumn{5}{|l|}{ Maternal parenting style score } \\
\hline \multicolumn{5}{|l|}{ All-cause mortality } \\
\hline Deaths, $n$ & 58 & 64 & 54 & 67 \\
\hline Deaths/1000 person-years (95\% Cl) & $19.6(15.2-25.4)$ & $21.0(16.5-26.9)$ & $25.1(19.2-32.8)$ & $27.4(21.6-34.9)$ \\
\hline Model 1, HR (95\% Cl) & 1.00 (reference) & $1.07(0.75-1.53)$ & $1.28(0.88-1.85)$ & $1.40(0.99-1.99)$ \\
\hline Model 2, HR (95\% Cl) & 1.00 (reference) & $1.01(0.71-1.44)$ & $1.23(0.85-1.79)$ & $1.56(1.10-2.23)$ \\
\hline Model 3, HR (95\% Cl) & 1.00 (reference) & $0.98(0.68-1.39)$ & $1.18(0.81-1.71)$ & $1.48(1.04-2.11)$ \\
\hline Model 4, HR (95\% Cl) & 1.00 (reference) & $1.04(0.73-1.50)$ & $1.16(0.79-1.70)$ & $1.41(0.97-2.04)$ \\
\hline \multicolumn{5}{|l|}{ Sample sizes } \\
\hline Participants, $n$ & 544 & 561 & 398 & 461 \\
\hline Person years of follow-up & 2956 & 3045 & 2153 & 2441 \\
\hline \multicolumn{5}{|l|}{ Paternal parenting style score } \\
\hline \multicolumn{5}{|l|}{ All-cause mortality } \\
\hline Deaths, $n$ & 51 & 58 & 60 & 74 \\
\hline Deaths/1000 person-years (95\% Cl) & $19.6(14.9-25.8)$ & $21.6(16.7-27.9)$ & $23.8(18.5-30.6)$ & $26.6(21.2-33.4)$ \\
\hline Model 1, HR (95\% Cl) & 1.00 (reference) & $1.10(0.76-1.61)$ & $1.22(0.84-1.76)$ & $1.36(0.95-1.94)$ \\
\hline Model 2, HR $(95 \% \mathrm{Cl})$ & 1.00 (reference) & $1.19(0.81-1.73)$ & $1.24(0.85-1.80)$ & $1.57(1.10-2.25)$ \\
\hline Model 3, HR (95\% Cl) & 1.00 (reference) & $1.14(0.78-1.67)$ & $1.15(0.79-1.68)$ & $1.46(1.02-2.10)$ \\
\hline Model 4, HR (95\% Cl) & 1.00 (reference) & $1.21(0.82-1.78)$ & $1.08(0.74-1.59)$ & $1.38(0.95-2.00)$ \\
\hline \multicolumn{5}{|l|}{ Sample sizes } \\
\hline Participants, $n$ & 477 & 499 & 464 & 524 \\
\hline Person-years of follow-up & 2602 & 2686 & 2523 & 2784 \\
\hline \multicolumn{5}{|c|}{$\begin{array}{l}\text { a. Model 1: this is the unadjusted association; Model 2: adjusted for age and gender; Model } 3 \text { as model } 2 \text {, plus adjustment for childhood socioeconomic position (i.e. ownership of } \\
\text { the first-ever permanent residence, number of books in the household at age } 10 \text { years, and father's or main carer's occupational class at age } 14 \text { years); model } 4 \text { : as model } 3 \text {, plus } \\
\text { adjustment for adult socioeconomic position (i.e. education and total net household wealth), marital status, parenthood status, obesity (i.e. body mass index and waist circumference) } \\
\text { cognitive function, unhealthy behaviours (i.e. smoking and physical activity), social factors (i.e. social support and number of problems with social relationships), elevated depressive } \\
\text { symptoms and positive affect. } \\
\text { b. Both maternal and paternal parenting style scores ranged from } 0 \text { (poorest style) to } 21 \text { (optimal style). Optimal quartile: score } \geqslant 18 \text {; second optimal quartile: score from } \geqslant 16 \text { to } \\
<18 \text {; second poorest quartile: score from } \geqslant 14 \text { to }<16 \text {; and poorest quartile: score }<14 \text {. }\end{array}$} \\
\hline
\end{tabular}




\section{Strengths and limitations}

The use of rich longitudinal data and a national sample are obvious strengths of our study. A weakness of our study is its observational design, which makes it vulnerable to residual confounding. Although we were able to adjust our models for several key confounders, it is still possible that unaccounted for confounders influenced to an extent our findings. Supplementary analyses that excluded deaths that occurred up to 24 months after the baseline and adjusted for baseline comorbidities indicated that our findings are unlikely to be an artefact of reverse causality (i.e. scoring lower on the parenting style scale because of a serious health condition at baseline or proximity to death). Further supplementary analyses indicated that poor parenting style is a childhood risk factor that is associated with the risk of death independent of other known childhood risk factors such as childhood diseases and adverse childhood experiences. The observed negative confounding effect of age on the examined associations is not surprising given that older people tend to remember their past more positively than younger people (i.e. positivity effect). ${ }^{30}$ To ascertain that our data are not driven by this tendency we adjusted our models for positive affect that likely accounts for it and restricted our analysis to a narrower age range so that our sample represented only one generation.

Our work is vulnerable to measurement bias. The adjustment for positive and negative affect expectedly reduced mood-congruent memory bias (i.e. the influence of baseline mood on parenting style reports). Nevertheless, the retrospective measurement of parenting style, the long lag between the exposure and its measurement, the use of a short seven-item instrument that focused on only two dimensions of parenting and the potentially sensitive nature of perceived parenting style may have influenced our results. ${ }^{31,32}$ Our childhood socioeconomic position measures have been proven to be good predictors of health outcomes such as mortality and morbidity, but they were also retrospectively measured and thus potentially subject to bias. Non-response bias could have also influenced our results. Because non-response to the life-history survey and, in particular, to the childhood experiences section of it is likely to be related to poorer childhood experiences, we hypothesise that our findings are a conservative account of the true association between parenting style and mortality. To contribute to a better interpretation of our findings in relation to non-response, we present, in online Table DS9, an analysis of key characteristics of our study according to various non-response categories. Further, the relatively small number of deaths and the short follow-up period reduced the statistical power of our study and did not allow investigation of the long-term effect of parenting style on survival. Finally, the use of a sample of English community-dwellers aged 65 to 79 years reduces the generalisability of our results; their relevance to other cohorts and populations is unknown.

\section{Interpretation of our findings}

The inverse association between parenting style and all-cause, cancer and other mortality lends support to the idea that parenting style is associated with disease and survival at older ages in a systematic way. Parenting style can affect general susceptibility to disease, but our focus on mortality and not the initiation of pathological processes and incidence of disease does not allow for more definite conclusions on this issue. Our findings suggest that poor parenting style qualifies as a risk factor for cancer and thus could inform the debate about the relationship between psychosocial factors and cancer mortality. ${ }^{33}$ Further, our findings indicate that deaths from respiratory and external causes might be related to experiences of suboptimal parenting, but the lack of appropriate data precluded a more detailed analysis of this. The lack of an association between poor parenting style and cardiovascular death is unexpected given the importance of stress for cardiovascular disease and the formative role of negative childhood experiences for HPA-axis dysregulation and chronic stress. ${ }^{10-12}$ Notwithstanding the chance of a statistical artefact, a possible explanation for this finding is that the damaging effect of poor parenting on the circulatory system might be alleviated by the action of protective factors operating at later stages of the life course, for example the use of medication for high cholesterol or blood pressure. This was illustrated in a cohort of older Finnish adults, where parental separation in early childhood was associated with the use of cardiovascular medication, but not cardiovascular mortality. ${ }^{34}$

Our data indicate that suboptimal parenting style in childhood might be associated with mortality in old age via multiple mechanisms and pathways. Participants' affective and social problems and unhealthy behaviours appeared to be relevant. Parental and family characteristics are also expected to be pertinent to the examined associations. Childhood socioeconomic position partially explained the associations, but our analyses suggest that poor parenting style does not necessarily cluster with socioeconomic adversity. Based on the importance of parental psychopathology and personality for parenting, ${ }^{35}$ it is reasonable to assume the existence of mechanisms that link parental psychopathology and personality with offspring's increased risk of mortality at older ages via parenting. Although we lacked detailed data on parental health and personality, in supplementary analyses, we were able to adjust for retrospectively measured selfreported parental mental health and addiction problems up to age 15 years. This additional adjustment did not appear to affect the observed associations, except for the association between parenting style and other mortality, which was modestly attenuated. These findings seem to suggest that parental psychopathology is relevant to the association between parenting style and other mortality, which includes deaths from respiratory and external causes including accidents and suicides.

Our findings presuppose the existence of biological mediators, ${ }^{36}$ which induce modifications in the physiology, that, via multiple pathways, lead to increased risk of death at older ages. Epigenetic modifications caused by poor parenting in childhood are a candidate mediator. ${ }^{37} \mathrm{~A}$ recent study of leukocyte DNA in healthy adults found that a lower score on the PBI care subscale was associated with increased cytosine methylation in the promoter region of the glucocorticoid receptor gene NR3C1. ${ }^{38}$ Telomere shortening, a marker of cellular ageing, may also be a mediator given its association with early life adversity and parenting. ${ }^{39}$ Poor parenting is associated with stress in childhood and the dysregulation of the HPA axis, ${ }^{10-12}$ which can affect the thyroid, growth and gonadal axes function, ${ }^{40}$ the development and function of the central nervous system, and cognitive and emotional functioning ${ }^{12,41}$ and thus have long-term implications for adult health. ${ }^{3,5}$ Inflammation processes and the dysregulation of the immune system are also associated with early life stress and could also mediate the observed associations., ${ }^{3,40}$ In our supplementary analyses, baseline fibrinogen, but not C-reactive protein, explained a small part of the association between parenting style and all-cause mortality. This limited effect is an indication that inflammation might be relevant to the examined associations. Finally, earlier age at menarche and risky sexual behaviours in daughters, which are risk factors for reproductive cancer in women, are also associated with an unstable childhood environment and poor parenting ${ }^{42}$ and could mediate the observed associations. ${ }^{43}$ 


\section{Directions for future research}

Our findings are novel and need to be replicated in other older cohorts. Future research should examine the association between parenting style and mortality risk using a longer follow-up and a greater number of events. This would result in a more precise measurement of hazard ratios and confidence intervals. The use of parenting style data that have been collected in childhood would be a crucial addition to this research as such data are less susceptible to recall bias. To our knowledge this is unlikely to happen in the near future in the UK because of the lack of suitable data in UK cohorts older than 60 years.

Future research should also examine the associations between parenting style and incidence of disease to gain a better understanding of poor parenting as a factor affecting general susceptibility to disease. Further, emphasis should be placed on the identification of the biological mediators and life-course mechanisms involved in this association. Finally, it is important to identify potential generational differences in this association. The only way to achieve that is to examine how generalisable are our findings to younger generations once they reach the age of our sample.

\section{Implications}

Our study indicates that childhood experiences of poor parenting style have long-term implications for survival in later life. They extend current understanding about how childhood experiences might influence health and survival at older ages because they refer to the entire population of children and their everyday experiences and not just children with severe adverse experiences. The potentially modifiable nature of suboptimal parenting style as a risk factor enhances the importance and relevance of our findings for prevention and early life-intervention strategies.

Panayotes Demakakos, PhD, Demetris Pillas, PhD, Michael Marmot, FRCP, Andrew Steptoe, DSC, Department of Epidemiology and Public Health, University College London, London, UK

Correspondence: Panayotes Demakakos, Department of Epidemiology and Public Health, University College London, London, WC1E 6BT, UK; Email: p.demakakos@ucl.ac.uk

First received 12 Jan 2015, final revision 11 Aug 2015, accepted 13 Aug 2015

\section{Funding}

The English Longitudinal Study of Ageing is supported by the National Institute on Aging (Grants 2R01AG7644-01A1 and 2R01AG017644) and a consortium of the UK government Foundation professor. The funding bodies had no role in the study design; in the collection, analysis and interpretation of data; in the writing of the report; and in the decision to submit the article for publication.

\section{References}

1 Ben-Shlomo Y, Kuh D. A life course approach to chronic disease epidemiology: conceptual models, empirical challenges and interdisciplinary perspectives. Int J Epidemiol 2002; 31: 285-93.

2 Barker D. Fetal origins of adult disease: strength of effects and biological basis. Int J Epidemiol 2002; 31: 1235-9.

3 Miller GE, Chen E, Parker KJ. Psychological stress in childhood and susceptibility to the chronic diseases of aging: moving toward a model of behavioral and biological mechanisms. Psychol Bull 2011; 137: 959-97.

4 Repetti RL, Taylor SE, Seeman TE. Risky families: family social environments and the mental and physical health of offspring. Psychol Bull 2002; 128: 330-66.

5 Carroll JE, Gruenewald TL, Taylor SE, Janicki-Deverts D, Matthews KA, Seeman TE. Childhood abuse, parental warmth, and adult multisystem biological risk in the Coronary Artery Risk Development in Young Adults study. Proc Natl Acad Sci USA 2013; 110: 17149-53.
6 Brown DW, Anda RF, Tiemeier H, Felitti VJ, Edwards VJ, Croft JB, et al. Adverse childhood experiences and the risk of premature mortality. Am J Prev Med 2009; 37: 389-96.

7 Kelly-Irving M, Lepage B, Dedieu D, Bartley M, Blane D, Grosclaude P, et al. Adverse childhood experiences and premature all-cause mortality. Eur $\mathrm{J}$ Epidemiol 2013; 28: 721-34.

8 Galobardes B, Lynch JW, Davey Smith G. Childhood socioeconomic circumstances and cause-specific mortality in adulthood: systematic review and interpretation. Epidemiol Rev 2004; 26: 7-21.

9 Felitti VJ, Anda RF, Nordenberg D, Williamson DF, Spitz AM, Edwards V, et al. Relationship of childhood abuse and household dysfunction to many of the leading causes of death in adults. Am J Prev Med 1998; 14: 245-58.

10 Luecken LJ, Lemery KS. Early caregiving and physiological stress responses. Clin Psychol Rev 2004; 24: 171-91.

11 Gunnar M, Quevedo K. The neurobiology of stress and development. Annu Rev Psychol 2007; 58: 145-73.

12 Lupien SJ, McEwen BS, Gunnar MR, Heim C. Effects of stress throughout the lifespan on the brain, behaviour and cognition. Nat Rev Neurosci 2009; 10 434-45

13 Sleddens EFC, Gerards SMPL, Thijs C, de Vries NK, Kremers SPJ. General parenting, childhood overweight and obesity-inducing behaviors: a review. Int J Pediatr Obes 2011; 6: e12-27.

14 Chan TW, Koo A. Parenting style and youth outcomes in the UK. Eur Sociol Rev 2010; 27: 385-99.

15 Kawabata Y, Alink LRA, Tseng W-L, van IJzendoorn MH, Crick NR. Materna and paternal parenting styles associated with relational aggression in children and adolescents: a conceptual analysis and meta-analytic review. Dev Rev 2011; 31: 240-78.

16 Weich S, Patterson J, Shaw R, Stewart-Brown S. Family relationships in childhood and common psychiatric disorders in later life: systematic review of prospective studies. Br J Psychiatry 2009; 194: 392-8.

17 Parker G, Tupling H, Brown LB. A Parental Bonding Instrument. Br J Med Psychol 1979; 52: 1-10.

18 Todd AL, Boyce PM, Heath AC, Martin NG. Shortened versions of the Interpersonal Sensitivity Measure, Parental Bonding Instrument and Intimate Bond Measure. Pers Individ Dif 1994; 16: 323-9.

19 Parker G. The Parental Bonding Instrument: psychometric properties reviewed. Psychiatr Dev 1989; 7: 317-35.

20 Murphy $E$, Wickramaratne $P$, Weissman $M$. The stability of parental bonding reports: a 20-year follow-up. J Affect Disord 2010; 125: 307-15.

21 Enns MW, Cox BJ, Clara I. Parental bonding and adult psychopathology: results from the US National Comorbidity Survey. Psychol Med 2002; 32 997-1008.

22 Long EC, Aggen SH, Gardner C, Kendler KS. Differential parenting and risk for psychopathology: a monozygotic twin difference approach. Soc Psychiatry Psychiatr Epidemiol 2015; 50: 1569-76

23 Yap MBH, Pilkington PD, Ryan SM, Jorm AF. Parental factors associated with depression and anxiety in young people: a systematic review and metaanalysis. J Affect Disord 2014; 156: 8-23.

24 World Health Organization. International Statistical Classification of Diseases and Related Health Problems, Tenth Revision (ICD-10). WHO, 2004.

25 Radloff LS. The CES-D scale: a self-report depression scale for research in the general population. Appl Psychol Meas 1977; 1: 385-401.

26 Hyde $M$, Wiggins RD, Higgs $P$, Blane DB. A measure of quality of life in early old age: the theory, development and properties of a needs satisfaction model (CASP-19). Aging Ment Health 2003; 7: 186-94.

27 Brown DW, Anda RF, Felitti VJ, Edwards VJ, Malarcher AM, Croft JB, et al. Adverse childhood experiences are associated with the risk of lung cancer: a prospective cohort study. BMC Public Health 2010; 10: 311.

28 Lee C, White HR. Effects of childhood maltreatment on violent injuries and premature death during young adulthood among urban high-risk men. Arch Pediatr Adolesc Med 2012; 166: 814-20.

29 Shaffer JW, Duszynski KR, Thomas CB. Family attitudes in youth as a possible precursor of cancer among physicians: a search for explanatory mechanisms. J Behav Med 1982; 5: 143-63.

30 Carstensen LL, Turan B, Scheibe S, Ram N, Ersner-Hershfield H, SamanezLarkin GR, et al. Emotional experience improves with age: evidence based on over 10 years of experience sampling. Psychol Aging 2011; 26: 21-33.

31 Hardt J, Rutter M. Validity of adult retrospective reports of adverse childhood experiences: review of the evidence. J Child Psychol Psychiatry 2004; 45 260-73.

32 Susser $\mathrm{E}$, Widom CS. Still searching for lost truths about the bitter sorrows of childhood. Schizophr Bull 2012; 38: 672-5. 
33 Chida $Y$, Hamer M, Wardle J, Steptoe A. Do stress-related psychosocial factors contribute to cancer incidence and survival? Nat Clin Pract Oncol 2008; 5: 466-75.

34 Alastalo H, Räikkönen $\mathrm{K}$, Pesonen A-K, Osmond C, Barker DJ, Heinonen $\mathrm{K}$, et al. Cardiovascular morbidity and mortality in finnish men and women separated temporarily from their parents in childhood - a life course study. Psychosom Med 2012; 74: 583-7.

35 Kendler KS, Sham PC, MacLean CJ. The determinants of parenting: an epidemiological, multi-informant, retrospective study. Psychol Med 1997; 27 549-63.

36 Rutter M. Achievements and challenges in the biology of environmental effects. Proc Natl Acad Sci USA 2012; 109 (suppl 2): 17149-53.

37 Champagne FA, Curley JP. Epigenetic mechanisms mediating the long-term effects of maternal care on development. Neurosci Biobehav Rev 2009; 33: 593-600.
38 Tyrka AR, Price LH, Marsit C, Walters OC, Carpenter LL. Childhood adversity and epigenetic modulation of the leukocyte glucocorticoid receptor: preliminary findings in healthy adults. PLoS One 2012; 7: e30148.

39 Asok A, Bernard K, Roth TL, Rosen JB, Dozier M. Parental responsiveness moderates the association between early-life stress and reduced telomere length. Dev Psychopathol 2013; 25: 577-85.

40 Charmandari E, Kino T, Souvatzoglou E, Chrousos GP. Pediatric stress: hormonal mediators and human development. Horm Res 2003; 59: 161-79.

41 Pechtel P, Pizzagalli DA. Effects of early life stress on cognitive and affective function: an integrated review of human literature. Psychopharmacology (Berl) 2011; 214: 55-70.

42 Belsky J. The development of human reproductive strategies: progress and prospects. Curr Dir Psychol Sci 2012; 21: 310-6.

43 Milne FH, Judge DS, Preen DB, Weinstein P. Early life environment, life history and risk of endometrial cancer. Med Hypotheses 2011; 77: 626-32.

EXTRA

\section{psychiatry} in literature

\section{Sherlock Holmes: the case of the man with the mistaken diagnosis}

\section{Yaolin Zheng \& Paul O. Wilkinson}

D. I. LESTRADE: I suppose [Sherlock] likes having all the same faces back together; appeals to his ... his . . JOHN WATSON: Asperger's?

Sherlock Holmes is famous for his sharp wit, reclusive nature, powers of observation and talent for deduction. To this list the modern-day BBC adaptation of Conan Doyle's stories has added 'Asperger's' - or its DSM-5 term: autism spectrum disorder (ASD).

A throwaway comment from Dr Watson, Sherlock's friend, full-time 'assistant' and, importantly, a doctor, adds fuel to a longstanding online debate over whether the detective (as well as other fictional characters in popular media) has autism. Although psychiatrists might consider it inappropriate and unhelpful to 'diagnose' a fictional character based on their fictitious behaviour in a television show, the general public (and indeed screenwriters) are less hesitant to draw parallels with their own experiences and observations of psychiatric illnesses.

In some ways, labelling a character with ASD has become a dramatic plot device to inject new life into the old archetype of the antisocial flawed genius. The diagnosis is commonly used to explain a character's 'one track' mindset, their unusual expertise in niche subjects being presented as a 'special interest'. In Holmes' case, such an association is not unsubstantiated: his crimesolving pursuits do have many of the qualities of a 'special interest' in terms of their intensity and focus. They occupy most of his time to the exclusion of other everyday activities including eating and sleeping, and do seem to inspire something akin to the 'overwhelming excitement' that those with ASD describe - such that he finds it difficult not to talk about his deductions even when the setting is socially inappropriate or his audience uninterested. And while his deductions seem initially astounding, when explained step-by-step they seem ordinary, obvious even, remarkable only for his unusual allocation of attention to details others have overlooked and his extensive knowledge of forensic subjects. We might even speculate that Sherlock's talent for deductive reasoning could have developed out of a desire to 'solve' intellectually, from physical clues, the people and relationships he struggled to understand intuitively, from social ones.

The other trait commonly 'explained' using the ASD label is difficulties with social interaction and communication, also present in Holmes: difficulties with adjusting his behaviour to social context, decreased social reciprocity and a reduced interest in forming friendships. However, these are not significant enough to have prevented him from maintaining several lasting friendships. Nor does he have any impaired understanding of non-verbal communication and his own communication is rich and complex. In fact, fundamental to Sherlock's success as a detective is his aptitude for identifying and understanding others' emotions and motivations. He frequently manipulates and lies persuasively to obtain information, a behaviour requiring significant social-communication skills to carry out successfully. Indeed, by yoking this reincarnation of Sherlock Holmes to autism, the writers appear to conflate their character's voluntary disregard for the feelings of others and contempt for socia niceties with the genuine difficulties in social communication and empathy seen in people with autism. This demonstrates a disregard for that all-important component of any detective story: motive.

Just as medical dramas can influence health-seeking behaviours, unjustified use of psychiatric labels can perpetuate harmful misrepresentations - yet whose responsibility is this? For writers, the priority is entertainment over education; for psychiatrists, real, not fictional, patients.

The opening quote comes from the BBC series Sherlock (season 2, episode 2: 'The hounds of Baskerville', first aired in the UK on 8 January 2012) 